\title{
MATERNAL BEHAVIOR AND ALARM RESPONSE IN THE EGGPLANT LACE BUG, GARGAPHIA SOLANI HEIDEMANN (TINGIDAE: HETEROPTERA) ${ }^{1}$
}

\author{
By R. S. KeARnS ${ }^{2}$ and R. T. Yamamoto \\ Entomology Department \\ North Carolina State University \\ Raleigh, NC 27650
}

\section{INTRODUCTION}

Maternal behavior in the eggplant lace bug, Gargaphia solani Heidemann (Tingidae: Heteroptera) was first reported by Fink (1915). He described the female's guarding of the eggs and shepherding of the nymphs from leaf to leaf. $G$. solani is found on the native horse nettle (Solanum carolinense) and on the introduced eggplant (Solanum melongena). Overwintering adults appear in late spring, and females lay eggs in circular masses on the underside of leaves. Fink reported that the number of eggs is greater than 100, oviposition lasts 4 to 5 days, and the incubation period is about 6 days. Maternal care persists through the development of the nymphs, and the life cycle is approximately 20 days. Females observed in this study usually laid less than 100 eggs over a period of 3 to 4 days (Kearns 1980).

Maternal behavior has been reported for a number of heteropterans (Melber and Schmidt 1977) and for two other species of the genus Gargaphia: Gargaphia tiliae (Weiss 1919, Torre-Bueno 1935, Sheeley and Yonke 1977) and Gargaphia irridescens (Torre-Bueno 1942). These accounts give few details. The maternal behavior of $G$. solani has much in common with that exhibited by treehoppers (Membracidae: Homoptera) (Wood 1974, 1976a, 1976b, 1977 and Hinton 1977). The complex behavior patterns of membracids and of G. solani suggest that aggregations of these insects depend upon a

\footnotetext{
1Paper number 6950 of the Journal Series of the North Carolina Agricultural Research Service, Raleigh, North Carolina.

${ }^{2}$ This work was completed in partial fulfillment of the requirements for the degree of Master of Science in Entomology.

Manuscript received by the editor August 30, 1981.
} 
pheromonal communication system which facilitates group movements. In the membracids, there is indirect evidence for aggregation pheromones (Hinton 1976, 1977). Alarm pheromones of membracids are released only when the body wall is ruptured, and this type of release has not been reported for any other insects. Pheromones causing alarm responses are known to be present in at least 3 membracid species. They are interspecific in action but have not been identified (Nault et al. 1974).

This study reports an examination of the movements of $G$. solani aggregations on host plants with particular emphasis on the female's behavior.

\section{MATERIALS AND METHODS}

\section{MAINTENANCE OF INSECTS}

G. solani was collected from horse nettle growing in or near Raleigh, N.C., and aggregations were maintained for more than a year on horse nettle or eggplant either in the laboratory on a 16:8 light:dark cycle or in a greenhouse. The movements of nymphs were studied after an aggregation consisting of nymphs and a female had been transferred to a small sprig of horse nettle having an unbranched stem with 5 or more leaves. A piece of leaf containing a group was pinned to the upper surface of the second or third leaf from the bottom of a horse nettle stem. In time, the aggregation moved off the leaf fragment and onto the fresh leaf.

\section{FEEDING MOVEMENTS}

Feeding movements were measured in light, darkness, and with a light placed below the aggregation. Groups chosen for these studies were nymphs in the third or fourth instars, with smaller numbers of the other instars present. For dark conditions, an aggregation on a horse nettle sprig was placed in a tightly covered metal can which had been sprayed inside with a dull-finish black paint. Directional lighting was provided by placing the sprig or plant within a darkened enclosure and positioning a light about $0.6 \mathrm{~m}$ from the bottom of the plant.

\section{ALARM RESPONSE AND ALARM PHEROMONE}

G. solani nymphs exhibited an alarm response after they were presented with a nymph, freshly squeezed and held by fine forceps, 
Table 1. Elements of behavior of $G$. solani females when their broods were responding to alarm pheromone

\begin{tabular}{lc}
\hline \multicolumn{1}{c}{ Behavior } & $\begin{array}{c}\text { \% of responses } \\
\text { observed (1) }\end{array}$ \\
\hline 1. Female positioned slightly below exit axil & 17 \\
2. Female positioned at exit axil & 50 \\
3. Female positioned between axils & 39 \\
4. Female positioned at entrance axil & 61 \\
5. Female moved off leaf shortly after nymphs left & $78^{*}$ \\
6. Female followed nymphs onto new leaf & $78^{*}$ \\
7. Female returned to old leaf after group had moved & 33 \\
8. Female used at least one of the first four elements listed & $89^{*}$ \\
\hline
\end{tabular}

(1) 18 different trials

* Significant at the $95 \%$ confidence level (Binomial distribution. Table 2, partial sums, Eisenhart 1952. Confidence intervals, Table A-22, Natrella 1963.)

or a nymph pierced with a pin against a small disk of filter paper (after Nault et al. 1974). Blank disks of filter paper placed near an aggregation did not elicit an alarm response. Nymphs of $G$. solani were also collected and stored in a small container of chloroform. Several hundred were sufficient to provide a crude extract. Before the extract was tested for activity, the chloroform was allowed to evaporate from a small sample contained in a Pasteur pipette. The tip was then brought close to an aggregation, and the bulb was pressed gently to force the remaining volatile pheromone from the tip. As a control, a pipette with evaporating chloroform was also used. Chloroform vapors disturbed resting aggregations, causing individuals to move away from the pipette; but chloroform alone did not elicit a full alarm response with characteristic group movement to a new leaf. Alarm responses were studied under welllighted conditions with and without the female present.

\section{RECORDING OF DATA}

Observations were written, tape recorded, or photographed. Direction of movement of aggregations on the host plant was recorded as up, down, or "up and down" (part of the group moved up, part moved down). Movement up or down was considered "directed"; movement both up and down, "undirected". The new 
position of the group was recorded as $1,2,3$, or 4 or more leaves above starting position. The designation " 4 or more" included leaf no. 4 and several small leaves at the growing tip of the plant.

\section{RESULTS}

Egg masses of G. solani are deposited on the underside of leaves, and first instar larvae feed from the leaf surface between the eggs and then from the areas adjacent to the eggs. The larvae are usually in a compact circular formation while feeding, and the aggregation moves away from the oviposition site as leaf tissue is destroyed. Feeding sites become yellow or brown in color and also brittle. On a large eggplant leaf, nymphs may pass through several instars before consuming most of the leaf's soft tissue. On the relatively smaller horse nettle leaf, an aggregation consumes the edible portion of a leaf more quickly and then moves to another leaf.

\section{MOVEMENTS TO NEW FEEDING SITES}

Movements to new sites on the same leaf seemed to proceed gradually and with little intervention from the female. As individuals in the aggregation withdrew their stylets, they moved away from where they were feeding, bumping into adjacent nymphs. These bumped nymphs in turn withdrew their stylets and moved or milled about, bumping into other nymphs until the entire aggregation was activated. Movement from the feeding site to another feeding site on the same leaf then ensued. Movement to a new leaf usually occurred after $75 \%$ or more of the leaf was damaged and often lasted for about an hour. The parent female, also activated by the milling nymphs, usually moved slowly down the petiole while keeping close physical contact with the nymphs immediately behind her. If there was any break in contact, the nearest nymphs moved forward and touched the tips of the female's wings with their antennae, or the female turned around and touched her antennae to those of the nearest advancing nymphs. During one group movement, the female waited first at the axil of the new leaf and then on the underside of the petiole, as nymphs filed by her. This behavior was identical to that observed during alarm responses. On two occasions, the female seemed to initiate movement of the nymphs by forcing her way into the cluster of feeding nymphs; but this occurred only when the nymphs were in the earlier instars and were moving 
Table 2. Direction of movement of G. solani aggregations on a host plant

\begin{tabular}{|c|c|c|c|c|}
\hline \multirow[b]{2}{*}{ Feeding Movements } & \multicolumn{2}{|c|}{$\begin{array}{c}\text { Female Present } \\
\% \text { of groups observed }\end{array}$} & \multicolumn{2}{|c|}{$\begin{array}{c}\text { Female Absent } \\
\% \text { of groups observed }\end{array}$} \\
\hline & $\begin{array}{l}\text { Upward } \\
\text { movement }\end{array}$ & $\begin{array}{l}\text { Directed } \\
\text { movement }\end{array}$ & $\begin{array}{l}\text { Upward } \\
\text { movement }\end{array}$ & $\begin{array}{c}\text { Directed } \\
\text { movement }\end{array}$ \\
\hline In light & $82 *$ & $96 *(1)$ & 78 & $100 *(2)$ \\
\hline In darkness & $89^{*}$ & $100 *(2)$ & $100^{*}$ & $100 *(3)$ \\
\hline $\begin{array}{l}\text { Light source below } \\
\text { aggregation }\end{array}$ & 71 & $78 \quad(2)$ & 75 & $67 \quad(3)$ \\
\hline Alarm Response & & & & \\
\hline In light & $90^{*}$ & $100 *(4)$ & 62 & $67 \quad(5)$ \\
\hline
\end{tabular}

(1) 23 observations

(2) 9 observations

(3) 6 observations

(4) 19 observations

(5) 12 observations

* Significant at the $95 \%$ confidence level

from one surface of the leaf to the opposite surface. At no time was "herding" by the female observed as described by Fink (1915).

Movements to a new leaf were difficult to predict and lengthy to monitor. Because of time considerations, it was not feasible to make a statistical study of the female's total behavior pattern during these group movements. When a female was present, she led the group to a new leaf. In the absence of a female, the nymphs moved on their own. Females sometimes wandered about on adjacent leaves but usually returned to their aggregations.

\section{ALARM RESPONSES}

When an aggregation of the third through fifth instar nymphs of G. solani was alarmed with a squashed fifth instar nymph, the group responded quickly, usually within 10 seconds. The duration of the response was from 4 to 20 minutes. If the nymphs were on the top surface of the leaf they moved to the underside, and conversely. In either case, at least some of the nymphs moved quickly to the midrib and from there to the petiole of the leaf. At the exit axil, the nymphs moved up or down the stem; but they were more likely to move up the stem (Table 2, Female Present). During this activity, the female 


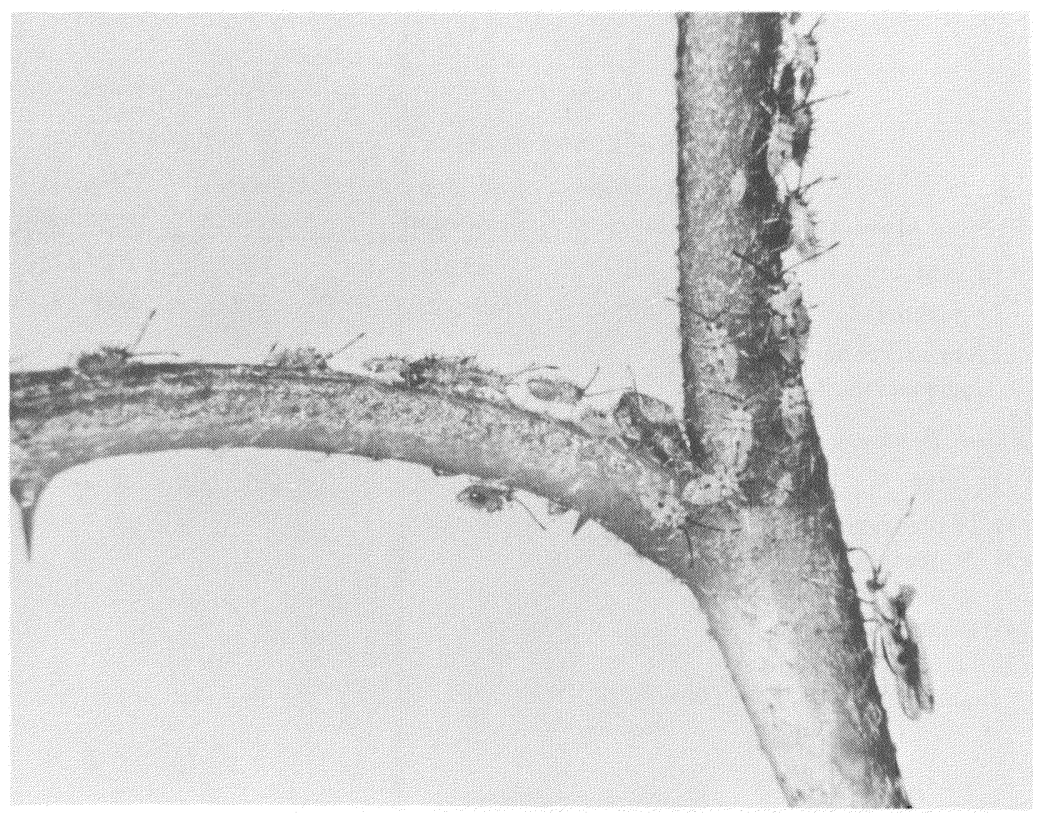

Figure 1. Adult female of $G$. solani positioned at the exit axil during an alarm response.

moved quickly to the axil of the leaf and oriented herself a little to one side of the nymphs' path (Fig. 1). When she was in this position, the nymphs moved up the stem rather than down.

As more of the nymphs left the leaf, the female sometimes moved about the axil and positioned herself along the side of the stem as the nymphs moved past her. When she was in these positions, she seemed to have little physical contact with the nymphs which filed past her unless they happened to bump into her in passing. Part way through an alarm response, the female moved quickly up the stem, usually to the axil of the first leaf above the previously occupied leaf. Many of the nymphs had already reached this axil and had moved down the petiole onto the new leaf. A few nymphs often proceeded above this axil and continued up the plant before returning to the group. The female oriented herself at the axil of the new leaf (Fig. 2) and waited there as more nymphs arrived. After most of the nymphs had passed along the petiole, the female joined the aggregation on the new leaf. 
There were always a few nymphs that remained behind or that failed to keep up with the bulk of the aggregation. These slower individuals wandered out onto other leaves but did not settle down until they found the group. Apparently the nymphs maintain locomotor activity unless they have sufficient physical or chemical contact with other nymphs. There were variations in the female's behavior (Table 1), but it was not obvious what environmental conditions might cause the female to include or change a particular element of her behavior. When an aggregation of first and/or second instars was alarmed, the group was likely to relocate on the same surface of the leaf rather than to move to the opposite surface or off the leaf.

Certain elements of the female's behavior were clearly recognizable and repeated more than once. These elements are recorded in Table 1 with the frequency of their occurrence in 18 different experimental responses to alarm pheromone. In $89 \%$ of the alarm responses, the female exhibited at least one of the first 4 elements

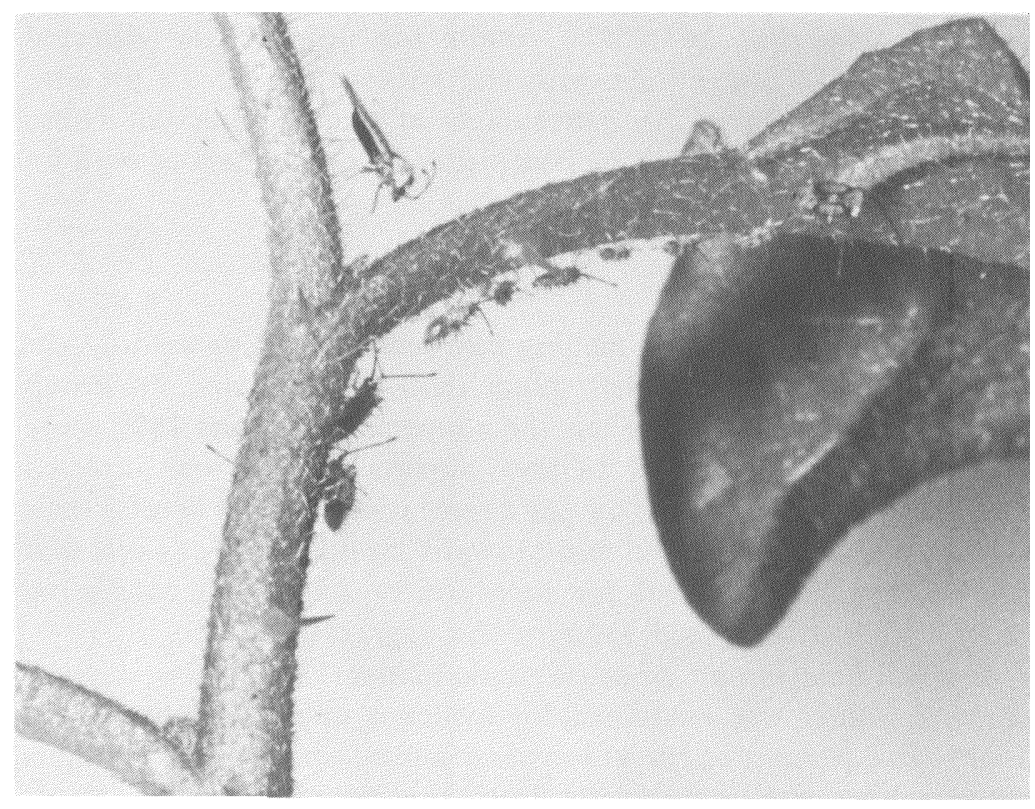

Figure 2. Adult female of $G$. solani positioned at the extrance axil during an alarm response. 
listed. The fourth element, female positioned at the entrance axil (Figure 2), was repeated most frequently, although the element was not itself significant. There was more variation in the female's position on the stem at the beginning of the alarm response than at the end.

\section{DIRECTION OF MOVEMENT}

Aggregations with and without the female present were studied in order to determine the significance of the female's role in feeding movements or alarm responses. It was hypothesized that the female's presence would keep the aggregation together and inhibit random movements on the plant. The relocation of the group was studied in terms of the direction of movement on the plant (up, down, or in both directions) and the choice of a new leaf on which to feed. Movement was considered directed if a group moved in one direction or the other, but not in both. A table for a binomial distribution was used to evaluate significance at the $95 \%$ confidence level (Table 2, partial sums, Eisenhart 1952; Table A-22, confidence intervals, Natrella 1963). The results for upward and directed movements of aggregations, with and without the female present, are recorded in Table 2 as percentages of groups observed. Those results significant at the $95 \%$ confidence level are marked with an asterisk.

\section{Feeding Movements}

In light or in darkness, feeding movements with or without the female prisent were directed rather than random, and the group usually moved upward. When the source of light was $180^{\circ}$ away from the usual direction, neither moving upward nor directed movement was significant; but the aggregations did not reverse their direction of movement and move toward the light. It is possible that the abnormal position of the light source acted as a conflicting stimulus which confused some of the aggregations.

A small field sample of horse nettle plants (13) showing damage from $G$. solani was examined for evidence of group movements. Eighty-five percent of the groups had moved upward on the plants from leaves containing the remains of egg masses. Moving up was significant at the $95 \%$ confidence level and closely matched the results obtained in the laboratory. 


\section{Alarm Response}

The female's presence or absence made a significant difference when the aggregation was alarmed. When the female was present, $90 \%$ of the groups moved upward, and $10 \%$ moved downward; but none split and moved in both directions. When the female was absent, $67 \%$ of the groups moved either upward or downward; onethird of the groups split.

\section{POSITION OF AGGREGATIONS FOLLOWING FEEDING MOVEMENTS OR ALARM RESPONSES}

The results of experiments for both feeding and alarm movements were combined, and a comparison was made between female present and female absent.

\section{Choice of Leaf}

With a choice of 4 leaf positions above the one occupied by the aggregation, the probability of an aggregation's reassembling on any one of the leaves was 0.25 . Using the binomial distribution (Eisenhart 1952), we compared the choice of leaf no. 1 with the choice of any other leaf (Table 3). Whether females were present or absent, the aggregations were more likely to move to leaf no. 1 than to any of the other leaves. If the aggregations split between leaves, the split usually included leaf no. 1. This behavioral pattern of the nymphs increased the likelihood that the group would remain together following movements on the host plant. When the female was present, the group was more likely to move as a unit to leave no. 1.

\section{Choice of Single or Multiple Leaves}

Movement to a single leaf was compared to movement to multiple leaves (Table 4). The probability associated with this choice was 0.5 . When females were present, aggregations usually moved as a unit to a single leaf on the host plant but when females were absent, aggregations split up as often as they chose a single leaf.

\section{WING FANNING BY THE FEMALE}

Fink (1915) reported that on one occasion he saw an adult female G. solani chase a ladybeetle (Hippodamia convergens Guer.) away 
Table 3. Choice of leaf position by $G$. solani aggregations following movements (1) on a host plant

\begin{tabular}{lcc}
\hline & \multicolumn{2}{c}{$\%$ of groups observed } \\
& Female Present & Female Absent \\
\hline Leaf no. 1 & 56 & 36 \\
Leaf no. 1 in combination with one or & 17 & 36 \\
$\quad$ more leaves & & \\
Total positions including leaf no. 1 & $72^{*}(2)$ & $71^{*}(3)$ \\
\hline
\end{tabular}

(1) Feeding movements and alarm responses combined

(2) 36 observations

(3) 14 observations

* Significant at the $95 \%$ confidence level

from an aggregation of feeding nymphs: the female "with outstretched, slightly raised wings suddenly darted toward the intruder, driving it from the leaf." In the laboratory, adult females of $G$. solani responded similarly (Fig. 3) to ladybeetles, anthocorids, ants, the tip of a brush, and a tomato pinworm caterpillar which was spinning a cocoon. Beamer (1930) and Wood (1976a, 1976b, 1977, and 1978) reported wing fanning in a total of 4 species of membracids. In each of these species, wing fanning was used by the adult female as a response to a predator (Beamer 1930; Wood 1976a, $1976 \mathrm{~b}, 1977$ ) or a threatening stimulus, such as a pencil used to prod the female (Wood 1978). Sheeley and Yonke (1977) observed wing fanning by the tingid Corythucha bulbosa when a jumping spider

Table 4. Choice of single or multiple leaves by G. solani aggregations following movements (1) on a host plant

\begin{tabular}{lcc}
\hline & \multicolumn{2}{c}{$\%$ of groups observed } \\
& Female Present & Female Absent \\
\hline Choice & & \\
Single leaf & $81^{*}(2)$ & $50(3)$ \\
Multiple leaves & $19(2)$ & $50(3)$ \\
\hline
\end{tabular}

(1) Feeding movements and alarm responses combined

(2) 36 observations

(3) 14 observations

* Significant at the $95 \%$ confidence level 
approached, and they reported that the spider's response to touching the tingid suggested the presence of a defensive chemical.

Wing fanning in G. solani occurred not only in response to a predator, but also under other circumstances. It was often associated with alarm responses and was directed toward the nymphs as well as toward a possible predator. For 27 brooding females, 143 occurrences of fanning were recorded in 2 categories: deterring a predator $(26 \%)$ and controlling the nymphs in one of several ways $(74 \%)$.

\section{Deterring Predators}

The brooding female responded to predators quickly after she detected their presence. The relatively large coccinellids (Hippodamia convergens, Olla abdominalis) were detected more readily than smaller predators such as Pharaoh ants (Monomorium pharaonis) or the anthocorid, Orius insidiosus. Attacks by ants and anthocorids were observed with a dissecting microscope. Females

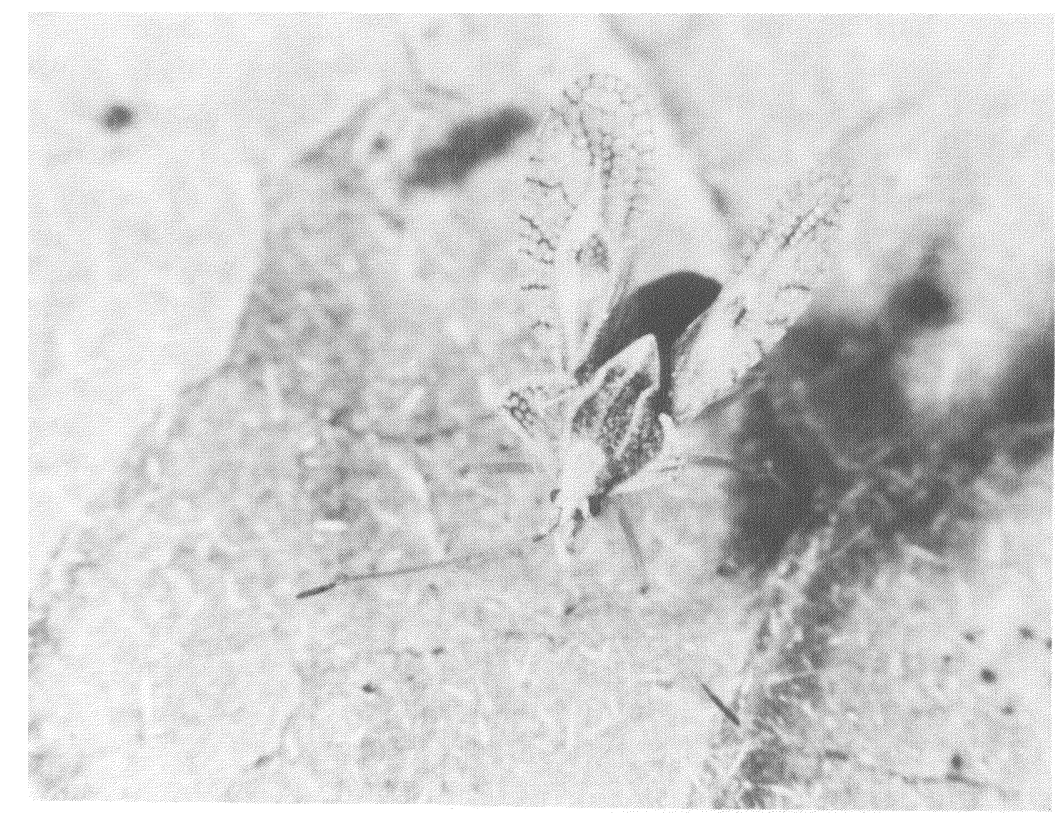

Figure 3. Adult female of $G$. solani fanning her wings. 
and nymphs failed to respond when a single ant removed an egg or ate a newly hatched first instar nymph. Ants carried tiny nymphs away from the brood, and the release of alarm pheromone was apparently not detected. When two or more ants moved in front of a brooding female, she responded with wing fanning and moved her body over the egg mass. Orius insidiosus nymphs, which were about the size of second instar $G$. solani nymphs, attacked their victims by penetrating intersegmental membranes. $O$. insidiosus was not always detected by the brooding female or nymphs, perhaps because the site of penetration was often in the coxal area rather than on the abdomen. When an attack occurred in front of a brooding female, she responded by fanning her wings and prodding the anthocorid with her head. Anthocorids responded by remaining motionless for periods of up to 55 minutes in length.

An attendant female responded to a coccinellid by rushing at it, fanning her wings, and, occasionally, by prodding it with her head. In 5 experiments with the adult coccinellid Hippodamia convergens, first and second instar nymphs were killed each time. In 3 of those encounters, the adult female lace bug was successful in driving away the coccinellid, preventing further loss of nymphs. In 2 encounters with starved coccinellids, the female lace bug was not able to drive the attacker away. The remaining nymphs survived because they fled apparently in response to an alarm pheromone released by crushed nymphs. In 3 encounters with the coccinellid Olla abdominalis, the female lace bug chased the approaching beetle successfully (Fig. 4); however, the beetle did not attack any nymphs or show much interest in them.

\section{Controlling Nymphs}

Females used wing fanning in their interactions with the nymphs. On at least 6 occasions, the attendant female went ahead of the moving aggregation and waited on the new leaf for the nymphs to arrive. While waiting for the nymphs, the females fanned their wings repeatedly.

There were a number of instances in which wing fanning was used to quiet a restless aggregation or one which had recently dispersed to a new leaf. The adult female circled the group with rapid, jerky movements and stopped occasionally to fan her wings. For 2 different females and aggregations, the female backed up to the 


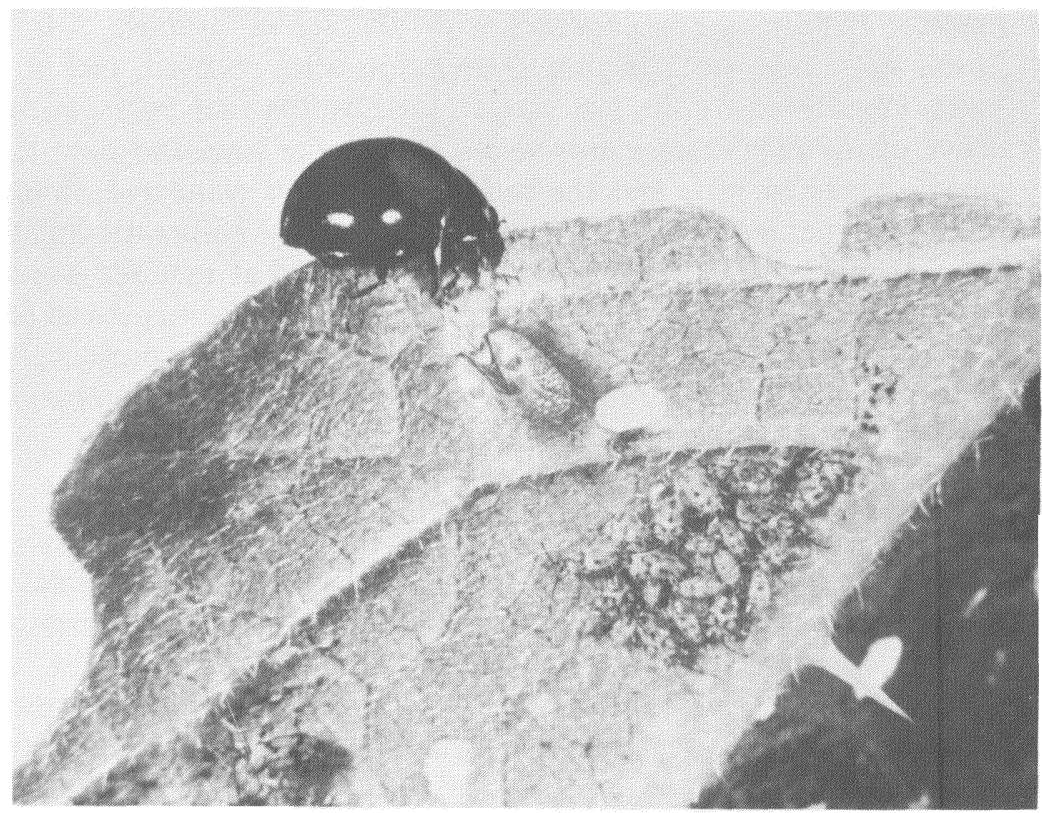

Figure 4. Adult female of G. solani responding to coccinellid, Olla abdominalis.

nymphs and pointed the tip of her abdomen toward them as she fanned her wings. This behavior suggests that the fanning may be used to propel a pheromone toward the group. One female was observed to use wing fanning to prevent the movement of an aggregation. The female was oriented at the base of the leaf, headed toward the group of nymphs. When 2 nymphs left the group, moved down the mid-vein, and approached her, she fanned her wings. The nymphs' response was a retreat.

\section{AGGREGATION}

There is some indirect evidence for an aggregation pheromone or for the nymphs' need for physical contact with each other. Upon hatching, nymphs feed near the egg mass for a short period and then move away as an aggregation. Older nymphs wander away from their own aggregations and join others, stray fifth instars being particularly conspicuous when they join groups of first and second 
instars. Following one experiment on the alarm response, 5 fifth instar nymphs from a second aggregation were released, one at a time, slightly above the leaf just vacated by the first aggregation. Four of the fifth instars moved directly up the stem and onto the newly occupied leaf, and the remaining nymph wandered about, first on higher leaves and then on the vacated leaf before moving to the occupied leaf. Other experiments showed that nymphs would reaggregate after they were separated by the experimenter. Need for physical contact might explain this adequately, but the presence of an aggregation pheromone should not be ruled out. Reaggregation is essential if the alarm response is to occur repeatedly.

\section{FEMALE'S BEHAVIORAL MATURATION}

Preliminary experiments (Kearns 1980) indicate that females undergo behavioral maturation from the time of oviposition through egg hatch and early development of the nymphs. Females at different stages of development were substituted for females which were attending aggregations of nymphs. Only those substitutes which had attended aggregations of their own behaved normally during an alarm response. When females which were still ovipositing were used as substitute mothers, they either avoided the alarmed nymphs or failed to interact with them.

\section{CHLOROFORM EXTRACT}

A chloroform extract of $G$. solani nymphs proved to be as effective in eliciting an alarm response as a fifth instar nymph squeezed with forceps or squashed on filter paper. Crushed adults also released the alarm pheromone, but the nymphal response was slower by a minute or less, to a crushed adult than to a crushed nymph. Preliminary attempts were made to test for alarm pheromones in 3 other tingids available locally: Corythucha ciliata, the sycamore lace bug; Corythucha cydoniae, the hawthorne lace bug; and Corythucha marmorata, the chrysanthemum lace bug. Nymphs of each species showed an alarm response to a crushed nymph of the same species. There were also cross responses between $G$. solani and each of the three species of Corythucha. Since not all three species of Corythucha overlap in time, it will be necessary to rear the insects in the laboratory or to make extracts of each for testing cross responses. 


\section{DISCUSSION}

Gargaphia solani and some of the membracids (Wood 1974, 1976b) are unusual in having maternal care extend from the time of oviposition through the maturation period of the nymphs. This long brooding period appears to be an adaptation to environments in which predation is an important factor. The host plants of $G$. solani grow close to the ground, and ants appear to be the most numerous predators. Maternal care in this tingid may have evolved as a response to ants or to low-flying predators or to both. Sheeley and Yonke (1977) were unable to find predators for some of the 7 species of tingids studied, perhaps because the host plants of 6 species are trees rather than small annuals. Gargaphia tiliae, having maternal care, might be expected to live close to the ground, but it is a treedwelling species. Sheeley and Yonke found no natural enemies of this insect, but the predators could have included tiny anthocorid nymphs which escaped detection.

It seems worthwhile to compare $G$. solani with some of the membracid species since there are striking similarities, including wing fanning by the attendant female and the release of an alarm pheromone when the body wall is ruptured. If $G$. solani and the membracids represent examples of parallel evolution, they may be responding to similar environmental stresses.

\section{Literature Cited}

BEAMER, R. H.

1930. Maternal instinct in a Membracid (Platycotis vittata) (Homopt.) Entomol. News 41(10): 330-331.

EISENhART, C.

1952. Tables of the Binomial Probability Distribution. National Bureau of Standards Applied Mathematics Series 6. U. S. Govt. Printing Office, Washington.

Fink, D. E.

1915. The eggplant lace-bug. Bull., U. S. Dept. Agricult. 239: 1-7.

Hinton, H. E.

1976. Maternal care in the Membracidae. Proc. Roy. Entomol. Soc. London (C). 41: 3-4.

1977. Subsocial behavior and biology of some Mexican membracid bugs. KEARNS, R. S. Ecological Entomology 2: 61-79.

1980. Maternal behavior in the eggplant lace bug Gargaphia solani Heidemann (Tingidae: Heteroptera). M.S. thesis, North Carolina State University, Raleigh. 
Melber, A., and G. H. Schmidt

1977. Sozialphanomene bei Heteropteren. Sonderdruck aus Zoologica. 127: 19-53.

Natrella, M. G.

1963. Experimental Statistics. National Bureau of Standards Handbook 91. U. S. Govt. Printing Office, Washington.

Nault, L. R., T. K. Wood, and A. M. GofF

1974. Treehopper (Membracidae) alarm pheromones. Nature 249: 387-388.

SheELEY, R. D. AND T. R. Yonke

1977. Biological notes on seven species of Missouri tingids (Hemiptera: Tingidae). J. Kansas Entomol. Soc. 50: 342-356.

Torre-Bueno, J. R.

1935. Notes on Gargaphia tiliae. Bull. Brooklyn Entomol. Soc. 30: 78.

1942. Maternal solicitude in Gargaphia iridescens Champion. Bull. Brooklyn Entomol. Soc. 37: 131.

WeISS, H. B.

1919. Notes on Gargaphia tiliae Walsh, the linden lace-bug. Proc. Biol. Soc. Wash. 32: 165-168.

WooD, T. K.

1974. Aggregating behavior of Umbonia crassicornis (Homoptera: Membracidae). Can. Ent. 106: 169-173.

1976a. Alarm behavior of brooding female Umbonia crassicornis (Membracidae: Homoptera). Ann. Entomol. Soc. Amer. 69: 340-344.

1976b. Biology and presocial behavior of Platycotis vittata (Homoptera: Membracidae). Ann. Entomol. Soc. Amer. 69: 807-811.

1977. Role of parent females and attendant ants in the maturation of the treehopper, Entylia bactriana (Homoptera: Membracidae). Sociobiology 2: 257-272.

1978. Parental care in Guayaquila compressa Walker (Homoptera: Membracidae). Psyche 85: 135-145. 

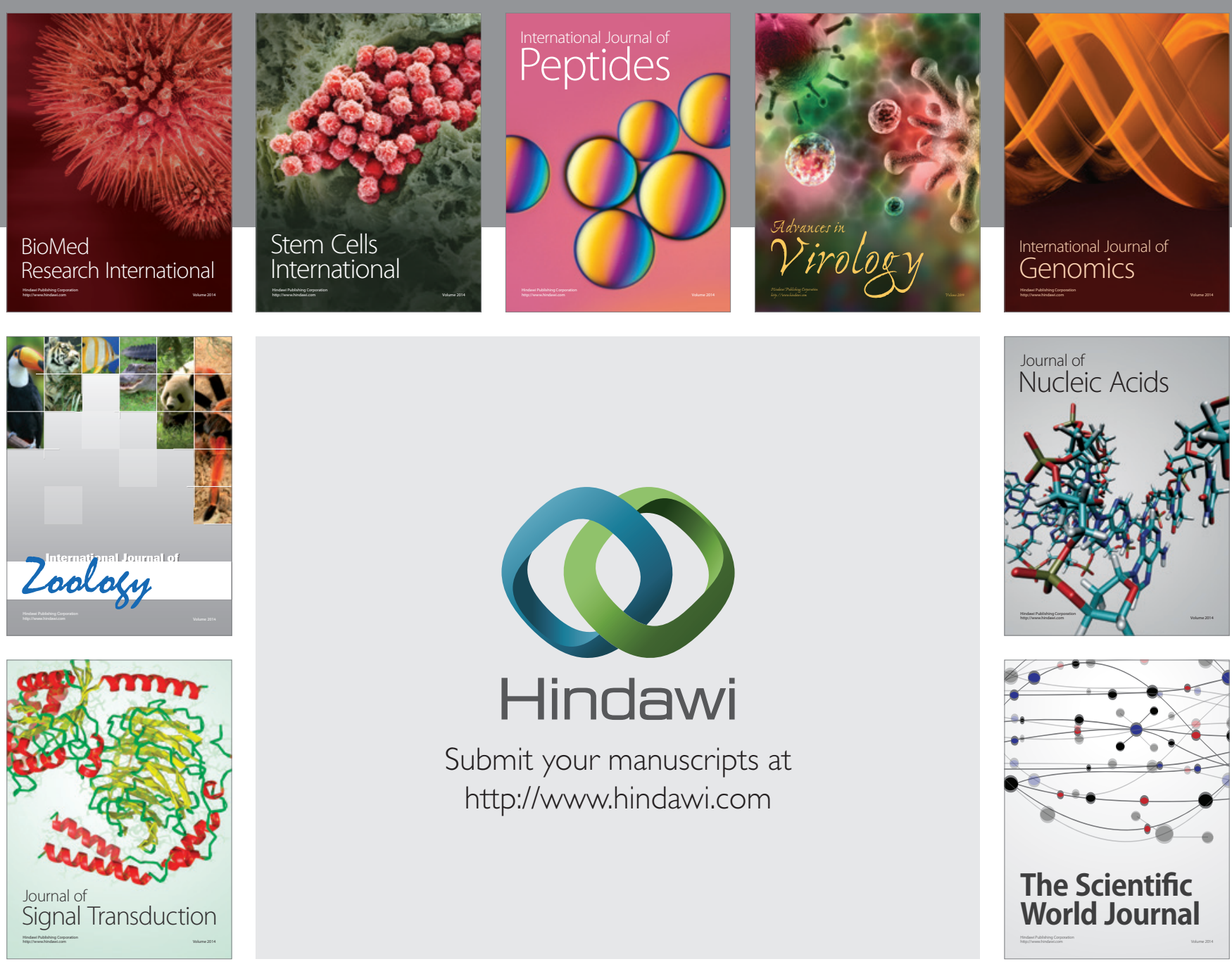

Submit your manuscripts at

http://www.hindawi.com
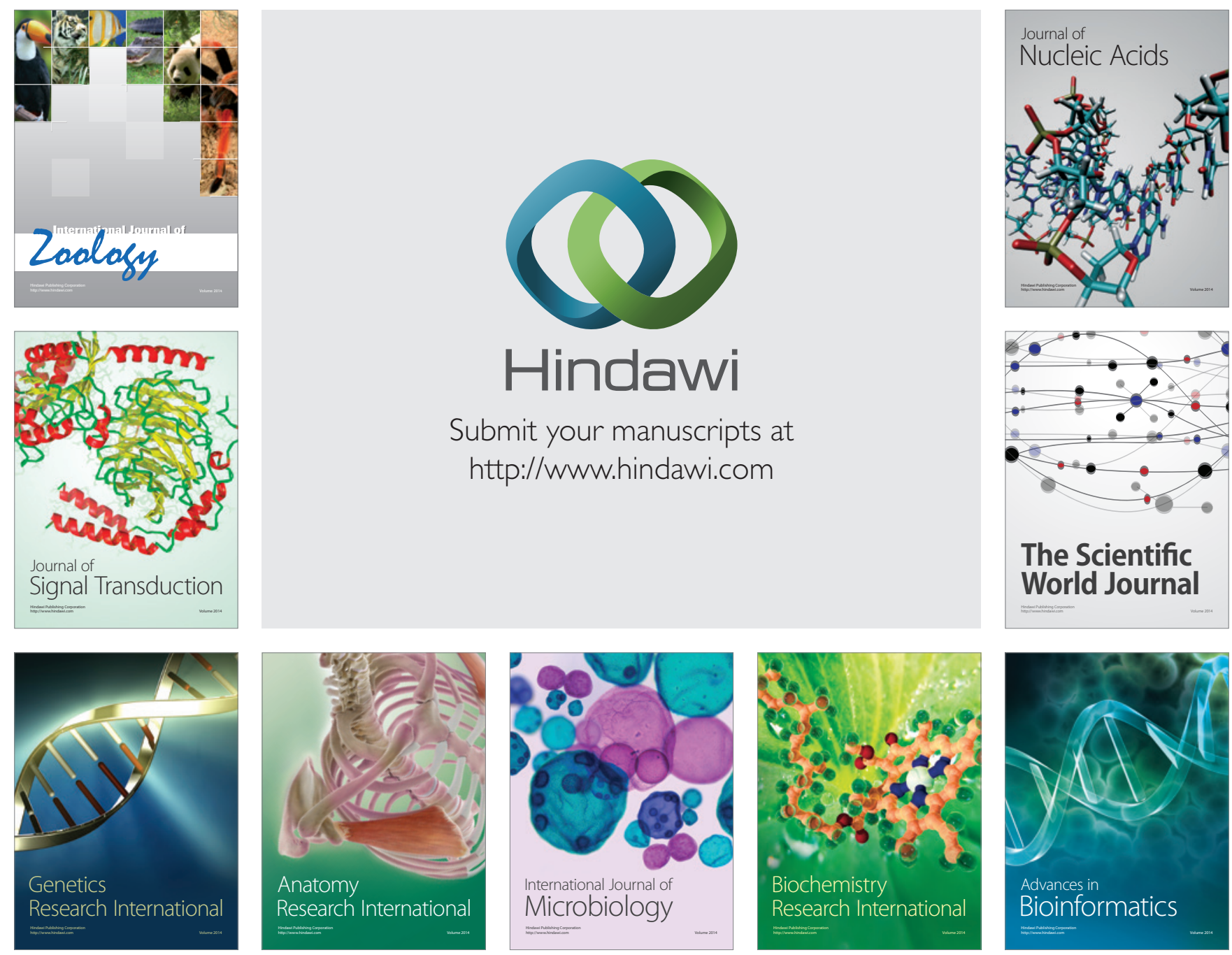

The Scientific World Journal
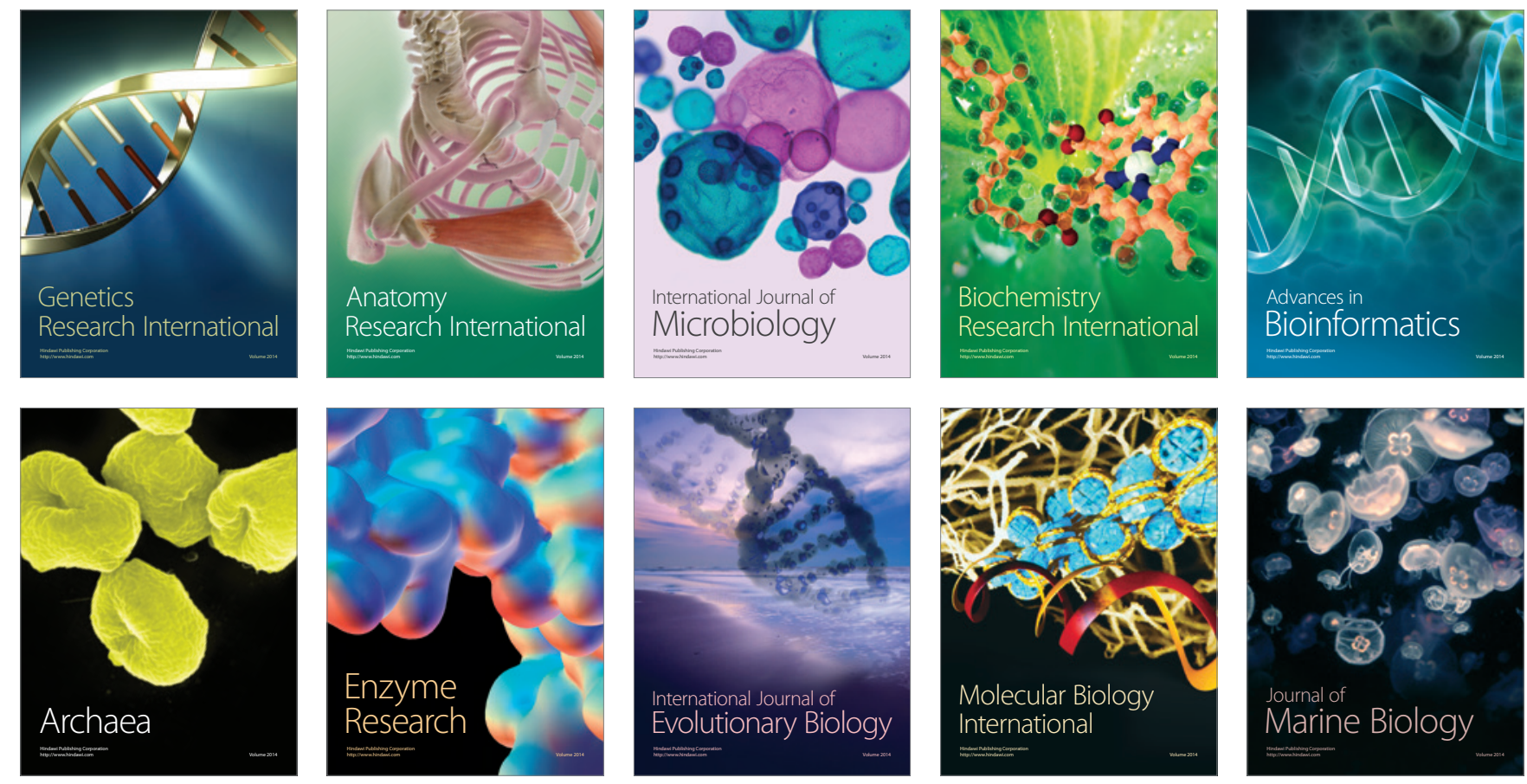